\title{
Ondernemingsvooruitskatting in die groot vervaardigingsondernemings in Suid-Afrika, 1978
}

\author{
Fanus C. Gous \\ Senior Lektor, Vakkomitee Bedryfsekonomie, Universiteit van Port Elizabeth, Port Elizabeth
}

Gebaseer op die outeur se D.Com. Proefskrif, Universiteit van Suid-Afrika, Pretoria, 1978

Business forecasting in the large manufacturing con. cerns in South Africa, 1978 Business forecasting has developed rapidly over the past few years as a result of the increasing complexity of the environment of the firm. Some overseas writers assert that the application thereof has developed more slowly than the theory connected to it: although businesses are aware of the necessity and existence of literature on the subject, it is only to a limited extent applied on an organized basis. Overseas businesses apparently experience three problems: a preference for the application of certain techniques is built up so that more suitable techniques are not utilized; not all relevant factors are taken into consideration in the choice of the most suitable technique; and managers often do forecasting themselves even though they possess little knowledge thereof. An empirical study has shown that similar problems are encountered by the relatively large manufacturing concerns in South Africa.

S. Afr. J. Bus. Mgmt 1979, 10: $125-130$

Ondernemingsvooruitskatting het gedurende die afgelope jare, as gevolg van die toenemende kompleksiteit in die ondernemingsomgewing, vinnig ontwikkel. Sommige oorsese skrywers beweer dat die toepassing daarvan stadiger ontwikkel het as die teorie daaraan verbonde: ondernemings, alhoewel bewus van die noodsaaklikheid daarvan en ook van die bestaan van literatuur daaroor, pas dit in 'n beperkte mate op georganiseerde grondslag toe. Blykbaar ondervind oorsese ondernemings veral drie probleme: 'n voorkeur vir die toepassing van bepaalde tegnieke word opgebou sodat meer toepaslike tegnieke nie benut word nie; alle relevante faktore word nie in ag geneem by die keuse van die tegniek nie; en bestuurders doen dikwels self vooruitskatting alhoewel hulle oor weinig kennis daarvan beskik. 'n Empiriese studie het getoon dat soortgelyke probleme deur die relatief groot vervaardigingsondernemings in Suid-Afrika ondervind word.

S.-Afr. Tydskr. Bedryfsl. 1979, 10: 125 - 130

Fanus C. Gous

Senior Lektor, Vakkomitee Bedryfsekonomie, Universiteit van Port Elizabeth, Posbus 1600 , Port Elizabeth 6000 , Suid-Afrika Ontvang 27 Julie 1979

*Nuwe adres: Departement van Bedryfsekonomie, Randse Afrikaanse Universiteit, Posbus 524, Johannesburg 2000, Suid-Afrika
Besluitneming kan as die primêre en kritiese aktiwiteit in die bestuurproses beskou word. Die sukses van 'n onderneming is derhalwe in die besonder afhanklik van die effektiwiteit van die besluitnemingsproses. ' Aangesien elke besluit wat in die onderneming geneem word op 'n vooruitskatting van die een of ander aard berus ${ }^{2}$ volg dit dat besluitneming verbeter of verswak na gelang van die kwaliteit van die vooruitskattings wat gedoen word. ${ }^{3}$

Ondernemingsvooruitskatting het gedurende die afgelope dekade, veral as gevolg van die toenemende komplekşiteit in die ondernemingsomgewing, vinnig ontwikkel. ${ }^{4}$ Dit geld sowel die teoretiese aspekte van vooruitskatting as die praktiese toepassing daarvan. Tog beweer skrywers soos Wheelwright en Makridakis, dat die praktyk stadiger as die teorie ontwikkel het, dit wil sê, dat ondernemings, alhoewel hulle van die noodsaaklikheid van wetenskaplike vooruitskatting asook van die bestaan van literatuur daaroor bewus is, vooruitskatting in beperkte mate op 'n georganiseerde grondslag toepas. Hierdie bewering word bevestig in verskeie empiriese studies wat veral in Noord-Amerika en Brittanje onderneem is. 5

Aangesien vooruitskatting selfs in lande soos die Verenigde State van Amerika en Brittanje nie behoorlik tot sy reg kom nie, het die vraag ontstaan in welke mate wetenskaplike ondernemingsvooruitskatting in die Republiek van Suid-Afrika gedoen word. 'n Empiriese ondersoek is derhalwe in Suid-Afrika onderneem met die doel om 'n kritiese analise te maak wat betref die gesofistikeerdheid van die toepassing van ondernemingsvooruitskatting en om aanbevelings te doen oor hoe om moontlike leemtes in die toepassing van ondernemingsvooruitskatting uit te skakel. Hierdie ondersoek is by die relatief groot vervaardigingsondernemings in SuidAfrika uitgevoer.

Drie redes kan aangevoer word vir die doen van die ondersoek by die relatief groot vervaardigingsondernemings in Suid-Afrika, te wete:

- 'n Ondersoek waarby alle ondernemings in SuidAfrika betrek word, sou té omvattend en heterogeen van aard wees

- Vervaardigingsondernemings is met sowel vervaardi- 
ging as bemarking gemoeid en het dus met besondere komplekse vooruitskatting te kampe. Die behoefte aan die toepassing van wetenskaplike en georganiseerde vooruitskatting behoort dus by vervaardigingsondernemings groter as by handelsondernemings te wees

- Groot ondernemings se vooruitskattingspogings behoort meer gesofistikeerd as dié van die klein ondernemings te wees, aangesien die middele (byvoorbeeld kapitaal en die gehalte van arbeid) tot die beskikking van groot ondernemings kwantitatief en kwalitatief gesproke normaalweg toereikender is as die middele tot beskikking van klein ondernemings.

As relatief groot vervaardigingsondernemings is geneem daardie ondernemings wat gedurende 1971/72 in elk van die 79 subgroepe van die Standaardnywerheidsklassifikasie van alle Ekonomiese Bedrywighede van die grootste tot die kleinste geneem, vir ongeveer $50 \%$ van die totale omset van elke subgroep verantwoordelik was, ofskoon die grootte van die omset van subgroep tot subgroep verskil het.

Hierdie metode van seleksie het meegebring dat die universum uit 1474 relatief groot vervaardigingsondernemings bestaan het en vraelyste is vir voltooiing en terugsending aan hierdie ondernemings gestuur. Altesaam 27,7\% (409) van die ondernemings het bruikbare vraelyste betyds vir verwerking teruggestuur. $\mathrm{Na}$ hierdie 409 ondernemings word verder in hierdie artikel as 'die ondernemings wat aan die studie deelgeneem het' verwys. Hierdie ondernemings is as verteenwoordigend van die universum bewys. ${ }^{6 . p p 12-16}$

\section{Bevindings on Aanbevelings}

Ondernemingsvooruitskatting is 'n aktuele onderwerp en die groot vervaardigingsondernemings in Suid-Afrika stel besonder belang daarin. Hierdie stelling blyk duidelik uit die onderstaande:

- Altesaam 409 bruikbare vraelyste (dit wil sê, 27,7\% van die vraelyste uitgestuur) is terugontvang

- Twaalf ondernemings het versoek dat die resultate van die studie aan hulle beskikbaar gemaak moet word, en 10 deelnemende vervaardigers het telefonies geskakel om oor die onderwerp te kommunikeer

- Nie minder nie as $67 \%$ van die ondernemings wat aan die studie deelgeneem het, het aangedui dat hulle ondernemingsvooruitskatting as baie belangrik ag. Slegs ongeveer $5 \%$ beskou ondernemingsvooruitskatting as onbelangrik. Ondernemings wat sterk mededinging ondervind en/of wie se produkte seisoensgebonde is en/of wat goedere vervaardig wat 'n afgeleide vraag het, beskou ondernemingsvooruitskatting in die algemeen belangriker as ondernemings wat nie aan hierdie faktore onderworpe is nie.

Alhoewel ondernemingsvooruitskatting aktueel is en ondernemings dit in 'n groot mate belangrik ag, blyk dit tog uit die bespreking wat volg, dat die groot vervaardigingsondernemings in Suid-Afrika se vooruitskattingspogings oor die algemeen besonder ongesofistikeerd is.
Die meeste van die groot vervaardigingsondernemings in Suid-Afrika skat wel die belangrikste interne faktore vooruit. In Tabel 1 word onder andere aangetoon dat $80 \%$ en meer van die deelnemende ondernemings hulle kapitaal- en materiaalbehoeftes, wins, kontantvloei en verkope formeel vooruitskat. Verkope word meer as enige ander van dié faktore, naamlik deur $94 \%$ van die groot vervaardigingsondernemings in Suid-Afrika, vooruitgeskat. Hierdie toedrag van sake is in 'n groot mate te verstane aangesien verkoopsvooruitskatting die basis van die verkoopsbegroting vorm en laasgenoemde op sy beurt die basis van die jaarbegroting is.

Tabel 1 Interne faktore wat formeel deur die groot vervaardigingsondernemings in Suid-Afrika vooruitgeskat word (1978)

\begin{tabular}{lcc}
\hline \multicolumn{1}{c}{ Interne faktor } & $\begin{array}{c}\text { Getal } \\
\text { ondernemings }\end{array}$ & $\begin{array}{c}\text { Persentasie van } \\
\text { ondernemings }\end{array}$ \\
\hline Verkope & 386 & 94 \\
Kontantvloei & 378 & 92 \\
Wins & 364 & 89 \\
Kapitaalbehoefte & 351 & 86 \\
Materiaalbehoefte & 327 & 80 \\
Arbeidskoste & 300 & 73 \\
Mannekragbehoefte & 294 & 72 \\
Verkoopsprys & 281 & 69 \\
Markaandeel & 234 & 57 \\
Koste van kapitaal & 224 & 55 \\
Nuwe produkontwikke- & 206 & 50 \\
ling & & \\
\hline
\end{tabular}

Vooruitskatting van eksterne faktore deur die groot vervaardigingsondernemings in Suid-Afrika laat veel te wense oor. Uit Tabel 2 blyk onder andere dat die eksterne faktor wat die meeste deur die groot vervaardigingsondernemings in Suid-Afrika vooruitgeskat word, naamlik mededinging, slegs deur $64 \%$ van die deelnemende ondernemings vooruitgeskat word. Ekonomiese faktore word deur $59 \%$, politieke en wetlike faktore deur $31 \%$ en demografiese faktore deur slegs $24 \%$ van die onernemings vooruitgeskat.

Bepaalde ekonomiese omgewingsveranderlikes (dikwels ekonomiese indikators genoem) kan in die vooruitskattingsproses gebruik word as indikators of aanwysers van interne faktore (byvoorbeeld verkope) en eksterne faktore (byvoorbeeld owerheidsoptrede). So byvoorbeeld kan die bruto binnelandse produk dui op die verkope van 'n onderneming se produkte en die inflasiekoers op owerheidsoptrede. Hierdie ekonomiese indikators is besonder nuttig vir doeleindes van vooruitskatting aangesien hulle kwantitatief van aard is, heelwat Suid-Afrikaanse publikasies inligting daaroor bevat, en die gebruiksmoontlikhede daarvan redelik algemeen bekend is. Tog is gevind, soos in Tabel 3 aangetoon, dat die groot vervaardigingsondernemings in Suid-Afrika in die algemeen nie die waarde van die ekonomiese indikators vir doeleindes van vooruitskatting ten volle besef nie. Dit blyk byvoorbeeld uit Tabel 3 dat ekonomiese indikators soos die bruto binnelandse produk, besteebare inkome, werkloosheid, groothandelsprysindeks, uitvoer, invoer en residensiële 
Tabel 2 Besonderhede van eksterne faktore wat formeel deur die groot vervaardigingsondernemings in Suid-Afrika vooruitgeskat word (1978)

\begin{tabular}{|c|c|c|}
\hline Eksterne faktor & $\begin{array}{c}\text { Getal } \\
\text { ondernemings }\end{array}$ & $\begin{array}{c}\text { Persentasie van } \\
\text { ondernemings }\end{array}$ \\
\hline Mededingingsfaktore & 262 & 64 \\
\hline $\begin{array}{l}\text { Ekonomiese faktore (bv. } \\
\text { tendense in ekonomiese } \\
\text { groei) }\end{array}$ & 243 & 59 \\
\hline $\begin{array}{l}\text { Beskikbaarheid van kapi- } \\
\text { taal }\end{array}$ & 227 & 56 \\
\hline $\begin{array}{l}\text { Beskikbaarheid van ma- } \\
\text { teriaal }\end{array}$ & 217 & 53 \\
\hline $\begin{array}{l}\text { Beskikbaarheid van man- } \\
\text { nekrag }\end{array}$ & 173 & 42 \\
\hline $\begin{array}{l}\text { Tegnologiese faktore (bv. } \\
\text { wetenskaplike ontwikkel- } \\
\text { ings) }\end{array}$ & 158 & 39 \\
\hline $\begin{array}{l}\text { Politieke en Wetlike fak- } \\
\text { tore (bv. buitelandse hou- } \\
\text { ding }\end{array}$ & 126 & 31 \\
\hline $\begin{array}{l}\text { Demografiese faktore (bv. } \\
\text { bevolkingsgrootte en in- } \\
\text { kome) }\end{array}$ & 97 & 24 \\
\hline $\begin{array}{l}\text { Sosiale en kulturele fak- } \\
\text { tore (bv. behuising en } \\
\text { diensplig) }\end{array}$ & 94 & 23 \\
\hline $\begin{array}{l}\text { Militêre faktore (bv. } \\
\text { nasionale diensplig) }\end{array}$ & 54 & 13 \\
\hline $\begin{array}{l}\text { Beskikbaarheid van } \\
\text { ondernemerskap }\end{array}$ & 49 & 12 \\
\hline $\begin{array}{l}\text { Geografiese gesteldheid } \\
\text { (bv. klimaat) }\end{array}$ & 43 & 11 \\
\hline
\end{tabular}

Tabel 3 Die belangrikste ekonomiese indikators wat deur die groot vervaardigingsondernemings in Suid-Afrika vir vooruitskatting gebruik word (1978)

\begin{tabular}{lcc}
\hline \multicolumn{1}{c}{ Indikator } & $\begin{array}{c}\text { Getal } \\
\text { ondernemings }\end{array}$ & $\begin{array}{c}\text { Persentasie van } \\
\text { ondernemings }\end{array}$ \\
\hline Besteebare inkome & 99 & 24 \\
Bruto binnelandse produk & 132 & 32 \\
Kleinhandelsverkope & 170 & 42 \\
Werkloosheid & 70 & 17 \\
Groothandelsprysindeks & 110 & 27 \\
Verbruikersprysindeks & 166 & 41 \\
Uitvoer & 119 & 29 \\
Invoer & 100 & 24 \\
Rentekoerse & 191 & 47 \\
Industriële produksie & 153 & 37 \\
Residensiële konstruksie & 103 & 25 \\
Fiskale en monetêre maat- & & \\
reëls & 152 & 37 \\
Ekonomiese groeikoers & 253 & 93 \\
Inflasiekoers & 379 & \\
\hline
\end{tabular}

konstruksie deur minder as een derde van die groot vervaardiginsondernemings in Suid-Afrika gebruik word vir vooruitskatting.

Aangesien eksterne faktore 'n beeld van die onderneming se eksterne omgewing verskaf en dikwels 'n aandui- ding gee van die toekomstige verloop van sekere interne veranderlikes soos verkope en wins, is deeglike vooruitskatting van die eksterne faktore besonder belangrik. Dit stel die topleiding van ' $n$ onderneming in staat om behoorlike strategiese beplanning te doen, en daar word dus aanbeveel dat die groot vervaardigers in Suid-Afrika doelbewuste pogings aanwend om eksterne faktore self vooruit te skat of dat sodanige vooruitskattings van eksterne bronne bekom word.

Dit blyk dat daar besondere inligtingsprobleme met ondernemingsvooruitskatting in Suid-afrika ondervind word. So het $55 \%$ van die groot vervaardigingsondernemings byvoorbeeld in die eerste plaas aangetoon dat ' $n$ gebrek aan genoegsame akkurate en relevante data die ontwikkeling en/of effektiwiteit van hulle ondernemings se vooruitskattingspogings aan bande lê. Die stelling kom vreemd voor aangesien daar 'n groot verskeidenheid publikasies van staats- en ander instellings in Suid-Afrika bestaan wat eksterne data bevat. Voorbeelde van sulke publikasies is dié van handelsbanke, die Wetenskaplike en Nywerheidsnavorsingsraad, buro's en institute van universiteite en die Departement van Omgewingsbeplanning en van Energie. Weinig van die publikasies word egter benut en selfs dié wat die meeste benut word, byvoorbeeld die publikasies van die Buro vir Ekonomiese Ondersoek en die Departement van Statistiek, word deur slegs $15 \%$ van die groot vervaardigingsondernemings gebruik. Moontlike redes waarom publikasies as bron van inligting deur die groot vervaardigingsondernemings afgeskeep word, is dat:

- slegs 'n klein persentasie van die ondernemings eksterne faktore vooruitskat

- slegs 'n klein persentasie van die ondernemings van ekonomiese indikators gebruik maak

- die verantwoordelikheid om publikasies te ontleed, normaalweg nie aan spesifieke persone of afdelings in die ondernemings opgedra word nie

- heelwat verskillende publikasies verkry moet word ten einde die nodig eksterne inligting vir vooruitskattingsdoeleindes te bekom.

In die lig van die voorgaande word die volgende aanbevelings gedoen:

- Die groot vervaardigingsondernemings in SuidAfrika moet 'n spesifieke poging aanwend om die bestaande publikasies van owerheids- en ander instellings te benut vir vooruitskatting. Die taak om gepubliseerde data te verkry, te ontleed en beskikbaar te stel vir vooruitskatting, behoort aan 'n spesifieke persoon of afdeling in ' $n$ onderneming opgedra te word

- Die moontlikheid moet ondersoek word om 'n sentrale instelling in die lewe te roep wat die bestaande publikasies op kontinue basis kan bekom en ontleed en vervolgens die belangrikste inligting vir ondernemingsbesluite in ' $n$ enkele publikasie saamvat. So 'n publikasie kan dan aan vervaardigers en ander ondernemings beskikbaar gestel word.

'n Tweede inligtingsprobleem wat ondervind word, is die gebrek aan interne data. Nie minder nie as $13 \%$ van die groot vervaardigingsondernemings het byvoorbeeld aangetoon dat 'n gebrek aan genoegsame akkurate en 
relevante interne data die ontwikkeling en/of effektiwiteit van die onderneming se vooruitskattingsaktiwiteite aan bande lê. Hierdie probleem hang ten nouste saam met die feit dat vervaardigingsondernemings nie voldoende gebruik maak van databanke en rekenaars nie. Sodanige huipmiddele help om genoegsame akkurate en relevante interne data vir vooruitskattingsdoeleindes te verkry.

Daar is derdens deur $11 \%$ van die ondernemings aangetoon dat die kompleksiteit van die beskikbare data die ontwikkeling en/of effektiwiteit van die onderneming se vooruitskattingsaktiwiteite aan bande lê. Sommige vooruitskattingstegnieke is natuurlik haas onbruikbaar indien die verwerkings nie op 'n rekenaar kan geskied nie.

Vierdens word daar 'n inligtingsprobleem ondervind omdat slegs $22 \%$ van die groot vervardigingsondernemings in Suid-Afrika oor 'n databank waar inligting op geordende wyse bewaar word, beskik. Daar word aanbeveel dat ondernemings meer van databanke gebruik maak.

'n Verdere inligtingsprobleem ontstaan omdat daar in beperkte mate van die rekenaar vir vooruitskatting gebruik gemaak word. Daar is trouens gevind dat slegs $19 \%$ van die groot vervaardigingsondernemings in SuidAfrika meestal of altyd van die rekenaar gebruik maak vir vooruitskattingsdoeleindes. Met die oog op die voordele wat die gebruik van die rekenaar vir vooruitskatting inhou, te wete tydsbesparing, akkuraatheid, kontinuïteit en die vermoë om komplekse verwerkings te doen, word daar aanbeveel dat die groot vervaardigingsondernemings in Suid-Afrika meer van rekenaars gebruik maak. Indien beperkte of geen rekenaarfasiliteite of gebrekkige kommunikasie tussen die vooruitskatter/bestuurder en die programmeerder die gebruik van rekenaars kortwiek, kan ondernemings moontlik gebruik maak van lessenaarrekenaars ('desk computers') wat redelik gesofistikeerde programme kan hanteer en relatief goedkoop en maklik hanteerbaar is.

Sesdens ontstaan daar ' $n$ inligtingsprobleem as gevolg van 'n gebrek aan effektiewe kommunikasie tussen die gebruikers en opstellers van vooruitskattings. Ongeveer $15 \%$ van die groot vervaardigingsondernemings in SuidAfrika toon trouens dat dié gebrek die ontwikkeling en/of effektiwiteit van hulle vooruitskattingsaktiwiteite aan bande lê. Een van die belangrikste redes vir die gebrek aan effektiewe kommunikasie is dat die gebruikers van die vooruitskattings nie voldoende kennis het van hoe hulle die vooruitskattings moet gebruik en hoe om vooruitskattings te doen nie. Daar word aanbeveel dat besondere aandag tydens opleiding in vooruitskatting, binne sowel as buite die onderneming, gegee word aan die verkryging en benutting van inligting, sowel as die oorbrugging van die kommunikasieprobleem tussen die gebruikers en die opstellers van vooruitskattings.

Relatief min groot vervaardigingsondernemings in Suid-Afrika maak van vooruitskattingspesialiste, dit wil sê, persone wat uitsluitlik vooruitskattings doen, gebruik. Die meeste groot vervaardigingsondernemings $(\mathbf{7 3 \%})$ beskik ook nie oor gesentraliseerde vooruitskattingsafdelings nie en beoog ook nie om sodanige afdelings in die lewe te roep nie. Dit bring mee dat die oorgrote meerderheid van die groot vervaardigingsondernemings in Suid-
Afrika nie die besondere voordele wat aan 'n gesentraliseerde afdeling verbonde is, verkry nie. ${ }^{6, p 213}$ In hierdie verband is daar aanbeveel dat die groot vervaardigingsondernemings met inagneming van die koste in verhouding tot die voordele wat daaruit voortvloei, aandag skenk aan die wenslikheid van die skepping van 'n gesentraliseerde vooruitskattingsafdeling, hoewel dit personeelgewys klein kan wees. Hierdie vooruitskattingsafdeling moet liefs direk aan die algemene bestuurder verantwoordelik wees. So 'n organisatoriese inskakeling geld trouens reeds vir meer as $80 \%$ van die groot vervaardigingsondernemings in Suid-Afrika wat wel oor gesentraliseerde vooruitskattingsafdelings beskik.

Dit blyk uit die ondersoek dat die groot vervaardigingsondernemings in Suid-Afrika grootliks vir die mediumen lang termyn, met ander woorde, vir drie maande en langer, vooruitskat. Slegs 4 en $25 \%$ van die groot vervaardigingsondernemings skat onderskeidelik vir die onmiddellike (minder as een maand) en kort termyn (een tot drie maande) vooruit. Aangesien daar, teoreties gesproke, vir elk van die onmiddellike, kort, medium- en lang termyne vooruitgeskat behoort te word, word daar aanbeveel dat die groot vervaardigingsondernemings in Suid-Afrika meer klem op vooruitskatting vir die onmiddellike en kort termyne moet laat val as wat tans die geval is.

Vooruitskattingstegnieke kan in twee breë groepe ingedeel word, naamlik kwantitatiewe en kwalitatiewe tegnieke van vooruitskatting. ${ }^{4 . \mathrm{pd}^{4}} \mathrm{Kwantitatiewe}$ vooruitskattingstegnieke behels die gebruik van kwantitatiewe data - wat feitlik sonder uitsondering histories van aard is - teneinde vooruitskatting te doen. Indien kwantitatiewe historiese data egter nie beskikbaar of bruikbaar is nie, geskied vooruitskatting deur middel van subjektiewe oordeel. Die tegnieke wat in laasgenoemde geval gebruik word, word kwalitatiewe vooruitskattingstegnieke genoem. ${ }^{4, p 5}$ Vir die gebruik van kwalitatiewe vooruitskattingstegnieke word daar dus hoofsaaklik van kwalitatiewe data, wat soms wel histories van aard is en soms nie, gebruik gemaak. ${ }^{7}$

Blykbaar ondervind die groot vervaardigingsondernemings in Suid-Afrika besondere probleme met die keuse van die mees toepaslike vooruitskattingstegniek. Die volgende bevindings is in hierdie verband gedoen:

- Hoewel $77 \%$ van die ondernemings aangetoon het dat hulle die beginsel om sover moontlik van kwantitatiewe tegnieke gebruik te maak, aanvaar, word daar ongeveer net soveel tyd aan vooruitskatting met behulp van kwalitatiewe tegnieke as aan dié met behulp van kwantitatiewe tegnieke bestee. Dít blyk uit die feit dat $36 \%$ van die ondernemings aangetoon het dat hulle meer tyd aan die gebruik van kwantitatiewe as aan kwalitatiewe tegnieke bestee, $31 \%$ meer tyd aan kwalitatiewe as aan kwantitatiewe tegnieke bestee en $33 \%$ net soveel tyd aan kwantitatiewe as aan kwalitatiewe tegnieke bestee

- Faktore wat by die keuse van 'n vooruitskattingstegniek in gedagte gehou moet word, word soms oor die hoof gesien. Selfs die faktor wat byvoorbeeld deur die meeste van die ondernemings in gedagte gehou word, naamlik die aard en die beskikbaarheid van historiese data, word deur slegs $76 \%$ van die 
ondernemings in ag geneem.

Gesofistikeerde vooruitskattingstegnieke word deur relatief min van die vervaardigingsondernemings in SuidAfrika gebruik, soos uit Tabelle 4 en 5 blyk.

Uit Tabel 4 blyk dat gesofistikeerde kwantitatiewe vooruitskattingstegnieke soos aanpassingsfiltrering, die klassieke tegniek van tydsreeksontbinding, Foran II, Census II en ekonometriese vooruitskatting, deur slegs $10 \%$ en minder van die ondernemings gebruik word.

Tabel 4 Kwantitatiewe vooruitskattingstegnieke wat deur die groot vervaardigingsondernemings in Suid-Afrika vir vooruitskatting gebruik word (1978)

\begin{tabular}{ccc} 
Getal & $\begin{array}{c}\text { Persentasie van } \\
\text { ondernemings }\end{array}$ \\
\hline
\end{tabular}

\begin{tabular}{lrr}
\hline $\begin{array}{l}\text { Eenvoudige rekenkundige } \\
\text { gemiddelde }\end{array}$ & 197 & 48 \\
$\begin{array}{l}\text { Persentasieveranderings- } \\
\text { metode }\end{array}$ & 224 & 55 \\
Geweegde gemiddelde & 129 & 32 \\
Bewegende gemiddelde & 198 & 48 \\
Eksponensiale gladstryking & 60 & 15 \\
Aanpassingsfiltrering & 8 & 2 \\
Tendensekstrapolasie & 115 & 28 \\
Klassieke tegniek van tyd- & & \\
reeksontbinding & 22 & 5 \\
Census II & 2 & 0 \\
Foran II & 2 & 0 \\
Box-Jenkinsmetode & 7 & 2 \\
Ekonometriese vooruit- & & 10 \\
skatting & 41 & 16 \\
Regressie en korrelasie & 67 & 4 \\
Inset-uitsettabelle & 18 &
\end{tabular}

Uit Tabel 5 blyk dat gesofistikeerde kwalitatiewe vooruitskattingstegnieke ook min benut word. Tegnieke soos die Delphi-tegniek, PERT en PATTERN, word onderskeidelik deur slegs 2,6 en $1 \%$ van die groot vervaardigingsondernemings in Suid-Afrika gebruik. Die belangrikste rede vir die swak benutting van gesofistikeerde kwantitatiewe en kwalitatiewe vooruitskattingstegnieke is waarskynlik dat die meeste bestuurders/vooruitskatters in die groot vervaardigingsondernemings in Suid-Afrika nie voldoende kennis van hierdie tegnieke het nie. 'n Voorkeur word derhalwe opgebou vir die enkele tegnieke wat hulle ken.

In die lig van die besondere probleme wat by die keuse van 'n geskikte vooruitskattingstegniek ter sprake is, word die volgende aanbevelings gedoen:

- Aangesien dit blyk dat kwantitatiewe vooruitskattingstegnieke meer objektief as kwalitatiewe vooruitskattingstegnieke is, behoort ondernemings in die eerste plek van kwantitatiewe tegnieke gebruik te maak vir sover dit toegepas kan word. Kwalitatiewe tegnieke behoort gebruik te word slegs indien kwantitatiewe tegnieke nie toepaslik is nie.

- Aangesien geen bepaalde vooruitskattingstegniek of groep tegnieke altyd die beste is om toe te pas nie, moet ondernemings die aard van die besluitneming-
Tabel 5 Kwalitatiewe tegnieke wat deur die groot vervaardigingsondernemings in Suid-Afrika vir vooruitskatting gebruik word (1978)

\begin{tabular}{lcc}
\hline \multicolumn{1}{c}{ Tegniek } & $\begin{array}{c}\text { Getal } \\
\text { ondernemings }\end{array}$ & $\begin{array}{c}\text { Persentasie van } \\
\text { ondernemings }\end{array}$ \\
\hline $\begin{array}{l}\text { Delphi-tegniek } \\
\text { Passing van krommes }\end{array}$ & 10 & 2 \\
$\begin{array}{l}\text { Nie-tydgebonde tegnolo- } \\
\text { giese vergelykings }\end{array}$ & 62 & 10 \\
$\begin{array}{l}\text { Morfologiese navorsings- } \\
\text { metode }\end{array}$ & - & 0 \\
$\begin{array}{l}\text { PATTERN ('Planning } \\
\text { Assistance through Tech- } \\
\text { nical Evaluation or Rele- } \\
\text { vance Numbers') }\end{array}$ & 3 & 1 \\
$\begin{array}{l}\text { Deskundige mening } \\
\text { Verbruikersvoorneme en } \\
\text { klantverwagting }\end{array}$ & 229 & 56 \\
$\begin{array}{l}\text { Vooruitskatting deur } \\
\text { verkoopspersoneel } \\
\text { PERT ('Programme Eva- } \\
\text { luation and Review Tech- } \\
\text { nique') }\end{array}$ & 231 & 56 \\
\hline
\end{tabular}

situasie met dié van die beskikbare kwantitatiewe en kwalitatiewe tegnieke vergelyk ten einde die beste tegniek vir die besondere situasie te kies. Die volgende faktore moet by die keuse in gedagte gehou word: die aard en die beskikbaarheid van historiese data; die mate van akkuraatheid wat vereis word; die tydsperiode waarvoor vooruitgeskat word; die tyd wat beskikbaar is vir die doen van die vooruitskatting; die koste teenoor die akkuraatheid van die vooruitskatting; die vaardigheid en kennis wat vir die toepassing van die tegniek vereis word; en die gemak waarmee die bestuurder die aannames en beperkings kan interpreteer

- Bestuurders en vooruitskatters moet hulle vergewis van die bestaande tegnieke $e^{8}$ sodat hulle objektief kan wees in die keuse van 'n vooruitskattingstegniek en hulle moet nie 'n bepaalde voorkeur vir sekere tegnieke opbou omdat hulle die ander nie kan toepas nie. Bestaande tegnieke kan ook aangepas word by die onderneming se spesifieke omstandighede. Spesifieke aandag behoort gegee te word aan sowel gesofistikeerde kwantitatiewe vooruitskattingstegnieke soos aanpassingsfiltrering, die klassieke tegniek van tydreeksontbinding, Census II, Foran II en ekonometriese vooruitskatting, as kwalitatiewe tegnieke soos die Delphi-tegniek, PERT en PATTERN.

Vervaardigingsondernemings openbaar 'n besondere gebrek aan kennis van vooruitskatting in die algemeen en vooruitskattingstegnieke in die besonder. Dié bewering word onder andere gestaaf deur die feit dat:

- ondernemings in groot mate van ongesofistikeerde vooruitskattingstegnieke gebruik maak - al die gesofistikeerde tegnieke word oor die algemeen deur minder as $10 \%$ van die groot vervaardigingsondernemings gebruik 
- $31 \%$ van die ondernemings aangetoon het dat 'n gebrek aan opgeleide personeel hulle vooruitskattingsaktiwiteite aan bande lê

- nie minder nie as $19 \%$ van die ondernemings aangetoon het dat 'n gebrek aan toepaslike vooruitskattingstegnieke hulle vooruitskattingsaktiwiteite aan bande lê terwyl hulle in der waarheid maar in beperkte mate van gesofistikeerde tegnieke gebruik maak

- ondernemingsprobleme ondervind om te besluit of hulle kwantitatiewe of kwalitatiewe tegnieke moet gebruik en ooglopend verkeerdelik net soveel van kwalitatiewe vooruitskattingstegnieke as van kwantitatiewe tegnieke gebruik maak

- 'n groot persentasie $(53 \%)$ van die groot vervaardigingsondernemings in Suid-Afrika nie van 'n verskil tussen vooruitskatting en begroting bewus is nie.

Die gebrek aan kennis wat by vervaardigingsondernemings oor vooruitskatting heers, en die feit dat nie minder nie as $31 \%$ van die ondernemings in Suid-Afrika aangedui het dat ' $n$ tekort aan opgeleide vooruitskatters die ontwikkeling en/of effektiwiteit van die betrokke onderneming se vooruitskattingsaktiwiteite aan bande lê, dui op ' $n$ behoefte aan akademiese opleiding. In hierdie verband moet daarop gelet word dat vooruitskatters aan besonder hoë akademiese vereistes moet voldoen, naamlik ' $n$ kennis van die onderneming in sy geheel insluitende van bestuur, ' $n$ bepaalde kennis van statistiese maatstawwe en konsepte, en 'n deeglike kennis van vooruitskatting, dit wil sê, hulle moet onder andere weet wat vooruitskatting is, waarom dit belangrik is, vir welke termyn (wanneer) dit gedoen moet word, deur wie en waar in die onderneming dit hanteer moet word en hoe vooruitskatting gedoen moet word. Daar word derhalwe aanbeveel dat daar in sowel voorgraadse as nagraadse handelsopleiding groter aandag aan ondernemingsvooruitskatting gegee word. Ondernemingsvooruitskatting is immers ' $n$ handelsaspek en nie minder nie as $48 \%$ van die hoofde van gesentraliseerde vooruitskattingsafdelings in die groot vervaardigingsondernemings in Suid-Afrika beskik oor die een of ander handelskwalifikasie.

\section{Slotopmerkings}

Volgens Wheelwright en Makridakis het ondernemings in die afgelope jare veral drie probleme in vooruitskatting ondervind, naamlik:

- 'n voorkeur word vir bepaalde tegnieke opgebou en ander word dan oor die hoof gesien

- alle relevante faktore word nie in ag geneem by die keuse van die regte vooruitskatingstegniek nie

- bestuurders moet dikwels self vooruitskatting doen alhoewel hulle slegs oor 'n beperkte kennis van vooruitskatting beskik..$^{9 . p 22-3}$

Hierdie drie probleme word duidelik ook deur die groot vervaardigingsondernemings in Suid-Afrika ondervind. Daar is aanbeveel dat die betrokke ondernemings wat een of meer van die gemelde probleme ondervind, oorweging skenk aan die gebruik van die wisselwerkende vooruitskattingstelsel wat deur Wheelwright en Makridakis ontwerp is en wat bekend staan as SIBYL-RUNNER. ${ }^{9, p p 11-12}$ Hierdie rekenaarstelsel vergemaklik die keuse van die vooruitskattingstegniek en doen vervolgens die vooruitskatting met behulp van die betrokke tegniek.

\section{Verwysings}

I PISTORIUS, C.W.I. in Raamwerk vir opleiding in inligtingsbestuur. 1975. Bedryfsl. 6(1): 26.

2 MORRELL, J. Management decisions and the role of forecasting. 1972. Penguin Books: Middlesex, p. 17.

3 CHISHOLM, R.K. \& WHITAKER, G.R. Forecasting methods. 1975. 9de Druk, Richard D. Irwin: Homewood, Illionois, p.1.

4 WHEELWRIGHT, S.C. \& MAKRIDAKIS, S. Forecasting methods for management. 1977. 2de Uitgawe, John Wiley \& Sons: New York, p. ix.

5 TURNER, J. Forecasting practices in British industry. 1974. Surrey Univ. Press: London, pp. 42-50.

6 GOUS, S.C. Ondernemingsvooruitskatting in die groot vervaardigingsondernemings in die Republiek van Suid-Afrika. Ongepubliseerde D.Com. Verhandeling, Universiteit van SuidAfrika, Pretoria, Suid-Afrika. 1978.

7 CHAMBERS, J.C., MULliCK, S.K. \& SMITH, D.D. How to choose the right forecasting technique. Harv. Bus. Rev. 49: 49.

$8 \mathrm{Vir}$ 'n bespreking van enkele bekende vooruitskattingstegnieke sien GOUS, S.G. Ondernemingsvooruitskatting in die groot vervaardigingsondernemings in die Republiek van Suid-Afrika, pp. 19-158.

9 WHEELWRIGHT, S.G. \& MAKRIDAKIS, S. Interactive forecasting. 1978. 2de Uitgawe, Hoden-Day Inc.: San Francisco. 